\title{
Yugoslavia: de las repúblicas de los consejos obreros a la guerra entre repúblicas
}

\author{
Antonio José Romero Ramírez \\ Universidad de Granada. Deparzamento de Sociología y Psicología Social \\ Campus de Carruja, s/n. 1807l Granada. Spain
}

\section{Resumen}

La guerra que hoy día enfrenta entre sí a los ex miembros de la antigua Yugoslavia nos brinda la oportunidad de abordar retrospectivamente el fenómeno de la autogestión yugoslava. Durante algunas décadas Yugoslavia llamó la atención del mundo entero, no sólo por la talla de su líder polf́tico, el mariscal Tiro, sino porque se pensó que allí estaba prosperando un modelo de sociedad -alternarivo al capitalismo y al socialismo de estado-, donde la clase obrera era capaz de crear su propio autogobierno.

Sin embargo, la promesa del socialismo autogestionario pronto degencró en una elitocracia que, apostada en los centros neurálgicos del poder, desde las empresas y las comunas hasta las repúblicas, sólo sirvió a un único objetivo: sus propios intereses, șentando así, en parte, las bases del conflicto actual. (Autor)

Palabras clave: socialismo autogesrionatio, organización del trabajo, recnocracia, burocracia.

Abstract. Yugoeslavia: from workers' councils to republics' war

Today's war between the ex-members of the old Yugoslavia gives us the oppottunity to confront retrospectively the former self-management. Many decades ago Yugoslavia was a model for the whole World, not only regarding the political Grearness of Marshall Tito, but also because its own way of Socialism was an alternative model for Capitalism and the traditional State Socialisme, with an worker's class having its own self-governement.

However, the promise of a new Socialism with self-management of the workers was becoming by an by a fraud. An elite of power took control of all the most importants centers in enterprises, communes and the Republics. Their only purpose was to keep under control the whole society for their self-interest. These former powers relations set up the premises for today's political Conflict. (Autor)

Key words: work organization, self-management socialism, technocracy, burocracy.

\section{Sumario}

\section{Introducción}

l. La autogestion y sus mecanismos de participación
2. La autogestión y sus consecuencias prácticas

Bibliografía 


\section{Introducción}

Antes de que la antigua Yugoslavia fuese conocida por esa brutal, cruenta y fratricida guerra que hoy día enfrenta entre sí a los que en el pasado fueron miembros de un mismo estado, su notoriedad se debió a causas bien distintas. Sobre restos de los imperios austro-húngaro y otomano, la naciente Yugosłavia, con el mariscal Tito a la cabeza, sorprendería al mundo entero con la experiencia más acabada de democracia industrial.

Recién terminada la II Guerra Mundial, Yugoslavia era una joven nación de una gran pobreza, escasa industria, una proporción muy elevada de analfabetismo y una gran diversidad histórica, cultural, religiosa y étnica. Además, había sufrido en su propio territorio, y entre sus propias gentes, las consecuencias descarnadas del fascismo - practicado por los croaras sobre los serbios y se preparaba para aventurarse por el insólito camino, para ella, del socialismo.

Sorprende, pues, que sobre estas bases se cimentase un proyecto de sociedad donde el hombre habría de ser más responsable de su situación y dueño de su destino. Ello implicaba, por tanto, una alteración profunda de las estructuras sociales y un nuevo sistema político acorde con un mayor protagonismo de la base de la sociedad. Un proragonismo que en el plano productivo se concretaba en la autogestión', pero que, sin embargo, rranscendía a otros niveles de la vida social, política y cultural. Yugoslavia emprendía asi la vía del socialismo autogestionario, con el firme propósito de crear en pie de igualdad su destino $^{2}$.

La división del mundo en dos bloques y la figura política del mariscal Tito son algunos de los factores sociohistóricos que auspiciaron esta vía yugoslava hacia el socialismo. En 1948 Yugoslavia era expulsada de la Kominform, y acto seguido retomaba con fuerza la doctrina del control obrero ${ }^{3}$ que el propio

1. Hay quien se muestra poco favorable a cmplear el vocablo "autogestión". En este sentido, Roberto Dorado (1976) criticaba que se había realizado una mala adaptación o traducción del término original al castellano, y que hubiese sido más acertado popularizar términos como: autogobierno, gestión colectiva o gestión comunitaria. Para este mismo auror, cl lenguaje político también habria contribuido a trivializar el término, a vaciarlo de contenidó, convirtićndolo en una idea mágica. Cuando lo único común a todas las personas que aspiran a un proceso autogestionario es su deseo de evitar la instalación de un "socialismo de cstado" o, como otros lo han denominado, un ucapitalismo de estado".

2. Roger Garaudy (1972), uno de los pensadores más creativos en su momento de la izquierda francesa, afirmaba que la aurogestión: “[... ]cuestiona al capiralismo en su fundamento, la propiedad privada de los medios de producción, $y$ en todas sus consecuencias: el poder derivado de esta forma de propiedad [...] cuesciona rodas las formas de burocracia y de jerarquia, tanto aquelfas que derivan del capitalismo como aquellas que derivan de una concepción aucoricaria y centralizada del socialismo[...] cuestiona el principio de delegación característico de la democracia formal burguesa, de tipo parlamentario, y del socialismo burocrático, donde el militante delega y se enajena en un dirigente que decide por éts.

3. Para una mejor comprensión de la doctrina del control obrero remitimos al lector interesado a la obra de los siguientes autores: Supek (1973), Chauvey (1970) y Blumberg (1968). 
Partido Comunista había puesto ya en práctica durante la II Guerra Mundial en casi todas las industrias abandonadas por sus propietarios, y que años antes el mismo Tito tuvo oportunidad de ver en acción en la España revolucionaría de la Guerra Civil, al formar parte de la XIV Brigada Anarquista (Maestú, 1976). Yugoslavia abandonaba así, rápidamente, el modelo soviético de economía dirigida e iniciaba su particular andadura.

En contra de la tradición histórica, los consejos obreros se implantaban en Yugoslavia de forma pacífica y, paradóficamente, lo que tantos sacrificios y esfuerzos fallidos había costado en otras partes a la clase obrera era ahora alentado desde el poder. Así, tras un brevísimo período de centralización total de la economía (1945-1948), el Partido Comunista devolvía el protagonismo usurpado a la sociedad yugoslava, quien se vería, por tanto, empujada a organizarse y a hacerse oír a todos los niveles de la vida social, política y cultural del país.

El aparato del partido y el estado quedaban así, al menos formalmente, relegados a un plano secundario, procurando dejar expedita la vía yugoslava hacia la autogestión. Las bases de este cambio quedarían plasmadas en la Constitución de 1953, según la cual la nueva organización social y política del país descansaría sobre la propiedad "social» de los medios de producción, la "autogestión" de los trabajadores en la economía y el "autogobierno" de los ciudadanos en la comuna.

Así pues, a diferencia de otros tipos de gobierno, el modelo de la autogestión yugoslava sería un modelo integral y globalizador, a través del cual sería posible implicar al individuo en todos los niveles de la realidad, ya fuese ésta de carácter laboral o de carácter sociopolítico. Sin embargo, como veremos, el funcionamiento real del sistema yugoslavo quedó muy lejos de ser un auténtico socialismo de autogestión.

\section{La autogestión y sus mecanismos de participación}

En el plano empresarial, los instrumentos con que cuenta la clase trabajadora para su participación directa en la toma de decisiones son: los colectivos obreros, o asambleas de personal, y los consejos obreros. Junto a estos órganos hemos de citar el comité de gestión y la dirección, en tanto que representantes de la parte técnica y directiva, para completar la estructura organizativa de la empresa yugoslava.

Existen, pues, dos poderes diferenciados: uno de gestión y otro de dirección, por lo que a uno le correspondería fijar la política de la empresa y al otro ejecutarla.

Por su parte, las asambleas de personal, como depositarias de la voluntad del colectivo obrero, cuentan con la facultad de adoptar las principales decisiones de política general, así como de constituir comisiones - con frecuencia de carácter consultivo- sobre una gran variedad de temas específicos: contratación, vivienda, reclamaciones, productividad, seguridad, higiene, etc. (Castillo, 1987). A ellas pertenecen la totalidad de los trabajadores, incluido 
el director, pudiendo ser todos electores y posibies candidatos a los puestos de gestión de la empresa.

En cuanto al otro órgano principal de autogestión —el consejo obrero-, su presencia es obligatoria en toda empresa con más de treinta trabajadores, y estaría constituido por la totalidad de la plantilla cuando se trate de empresas de pequeño tamaño; no obstante, el número de sus miembros varía en función de las dimensiones de la organización, siendo lo frecuente que oscile entre 15 y 120 miembros. Así mismo, todo consejo obrero es elegido por la colectividad obrera cada dos años, renovándose por mitades anualmente, aunque su mandato podría ser revocado en cualquier momento. Además, para evitar el anquilosamiento en el poder de sus miembros, éstos no podrían ser reelegidos inmediatamente después de la expiración de su mandato e, incluso, el director de la empresa tendría vetada su pertenencia al consejo obrero.

Por otra parte, los consejos obreros actúan a modo de asambleas legislativas, con amplios poderes para elegir y revocar el mandato del poder ejecutivo (comité de gestión y director), para adoptar los reglamentos internos de la empresa, para llevar a cabo sus planes financieros y de producción, sus programas de inversiones y amortizaciones, para aprobar el balance y las cuentas de la empresa, o dirigir la política de personal (de Pablo, 1976).

Dada la compiejidad de los temas abordados, el consejo obrero cuenta con "comisiones especializadas" que actuarían bajo su supervisión y control. Una de dichas comisiones -integrada por representantes del personal, del sindicato y de las autoridades locales - es la encargada de juzgar en concurso público a los candidatos a la dirección y a los puestos directivos. Los candidatos así elegidos podrán ejercer su mandato por cuatro años prorrogables, y en número de tres a once miembros constituirán un comiré de gestión, del cual el director es miembro de oficio.

Dicho órgano ejecutivo estará encargado de la gestión corriente de la empresa con arreglo a la política definida por el consejo. Concretamente, informa al consejo sobre el funcionamiento de la empresa, presenta los proyectos para su aprobación, controla las actividades del director y de sus colaboradores, y, en definitiva, prepara todo lo necesario para la toma de decisiones por parte de los trabajadores.

Por último, la estructura organizativa de la empresa yugoslava queda completa con la figura del director, quien, como responsable técnico y administrativo, ejerce directamente la inspección y vigilancia de su funcionamicnto, y representa a la empresa ante el estado u otra organización exterior, no puede contratar ni despedir al personal, y en asuntos de importancia necesita cl consentimiento previo del comité de gestión o del consejo obrero (de Pablo, 1976).

Ahora bien, la autogestión de los trabajadores en la empresa yugoslava no se reduce al ejercicio de sus derechos y deberes en estos órganos de participación, sino que se pretende descentralizar al máximo el gobierno de la empresa. En este sentido, la Constitución de 1974 creaba las llamadas uorganizaciones básicas de trabajo asociado" con el fin de que fuesen las unidades más elementales de gestión y de producción las responsables y las beneficiarias máxi- 
mas de los derechos económicos y de autogestión. El poder emanado así de la base se delegaría hacia otras unidades mayores, con lo cual la estructura jerárquica daría paso a una nueva estructura descentralizada, donde todos estarían implicados en la toma de decisiones, independientemente del lugar que ocupen en la organización.

Aun así, la autogesción sería un proceso inacabado si quedase relegada al mundo laboral. De ahí que la autogestión obrera en la empresa tenga su paralelismo en los niveles social y políico. Parafraseando la Constitución yugoslava de 1953, el pueblo trabajador dispone de la comuna como organización político-territorial y comunidad socioeconómica de base, y como principal instrumento, por tanto, para el autogobierno de las instituciones económicas, sociales y políticas.

De este modo, la organización comunitaria asegura el contacto directo y el control del individuo sobre aquellos asuntos que como ciudadano o como trabajador le pudiesen afectar. Siendo imprescindible, para ello, que la comuna renga una dimensión óptima, ni muy grande ni muy pequeña.

El órgano principal de autogobierno de la comuna es el comité popular, que, a su vez, está constituido por los miembros del consejo comunal y del consejo de productores. Estos últimos se componen, así mismo, de quince a veinte miembros, según el tamaño de la comuna.

Én uno y otro caso el mandato es por cuatro años, si bien los requisitos para ser elector son diferentes. Así, mientras que el consejo comunal es elegido por sufragio universal de todos los ciudadanos, el consejo de productores sólo sería el resultado de la elección de aquellos productores directos de las tres ramas de la economía: agricultura, industria y servicios.

En la labor de gobierno ambos órganos son ayudados por comisiones especializadas, sin embargo, la responsabilidad fundamental de la comuna descansa sobre la figura del presidente del comité popular. Él es quien coordina y supervisa la administración de la misma, y a quien debe rendir cuentas el secretario del comité popular - un funcionario profesional contratado para la gestión administrativa de la comuna-.

Por otra parte, los mismos principios que rigen la autogestión obrera en las empresas serían aplicables a las diversas instituciones sociales constirutivas de la comuna, como serían las escuclas, instituciones científicas, culturales y recreativas, de sanidad, de vivienda, etc. (de Pablo, 1976).

\section{La autogestión y sus consecuencias prácticas}

En función de lo anteriormente descrito, sería lícito esperar del modelo de la autogestión yugoslava un altísimo grado de concrol y de participación efectiva de la población trabajadora, tanto en los asuntos de la empresa como del resto de la sociedad. Sin embargo, el funcionamiento real del modelo yugoslavo quedó lejos del ideal autogestionario (Marzal, 1986). Las distintas etapas por las que pasa cl modelo, así como la naturaleza de la autogestión, devaluaron su carácter e hicieron de aquélla más un sistema de organización del trabajo, que 
un verdadero instrumento con el que pudiese contar la clase trabajadora para su propio autogobierno ${ }^{4}$. De la misma manera que el juego y el reparto del poder entre la nueva clase dominante - la tecnocracia y la burocracia-- y las limitaciones inherentes a lo que Bicanic (cfr. Lane, 1976) ha llamado expresivamente "socialismo de mercado", privarian de una posición relevante a la fuerza de trabajo.

Dicha situación vendría, en parte, provocada por los orígenes rurales de la mayoría de la clase trabajadora, ya que a su procedencia rural se unen stt escasa capacitación, sus bajos niveles culturales o su mentalidad tradicional, entre otros factores ${ }^{5}$. El ejercicio activo del control y del poder quedaría así en manos de quien pueda desentrañar la compleja maraña técnica y administrativa que acompaña a la vida organizacional. Cualidades de las que carece, pues, la clase obrera, pero que sí posee la tecnocracia, en función de su posición y de su preparación (Obradovic, 1975).

De hecho, son éstos, la tecnócratas, quienes ocupan la mayor parte de los cargos de los órganos de autogestión y quienes hacen valer sus decisiones cuando se trata, sobre todo, de cuestiones técricas ${ }^{6}$; una posición de predominio de los técnicos que se vería reforzada tras los aires liberalizadores y de mercado que llegan a Yugoslavia a partir de los años sesenta. Por estas fechas se produciría también la concentración del sistema bancario, que sólo guiará su política de concesión de créditos movida por crirerios de racionalidad y eficiencia. Como consecuencia, la tecnocracia, además de verse secundada en su posición, estaría mucho más atenta a las demandas provenientes del sector bancario que a las de los propios trabajadores.

4. El modelo yugoslavo jamás maduró en la autogestión, a pesar del ordenamiento legal y de los mecanismos creados para su implanración. Esta es la opinión de Roberto Dorado (1976), con la cual nos mostramos de acuerdo, para quicn sería mucho más lícito hablar de cogestión en referencia a la expericncia yugoslava, ya que: «[... Jel aparato del estado subsiste - aunque tenga voluntad de auroexrinción o de socializarse- $[\ldots]$ subsisten las organizaciones políricas y sindicales, [...] diferencias de estatus sociales y téenicos. De esta situación - de la existencia de diferentes esferas de intcrés y de competencias- proceden los problemas de su implantación.»

5. L.a sociedad yugoslava partía de niveles muy bajos de alfaberización y escolarización, todavía en los años setenta la tasa de analfabetos era demasiado elevada para tratarse de un país mediamamente desarrollado. El grado de cualificación de los trabajadores presentaba, asimismo, un panorama análogo, con una fuerza de trabajo escasamente preparada y especializada. Evidenremente, asi, sería difícil desterrar los valores de autoridad a los que la sociedad yugoslava se encontraba tan acostumbrada, - valores que entratían en contradicción directa con el nuevo espíritu autogestionario, tan profundamente inspirado en principios igualitarios-, ni la clase obrera se sentiría involucrada en su propia emancipación.

6. A principios de la decada de los secenta, nos informa de Pablo (1976), los obreros semicualificados y no cualificados, por aquel entonces el $39 \%$ de la fuerza laboral, representaban tan sólo un $16 \%$ en los consejos obreros, un $5 \%$ en los comités de gestión, y ocupaban la presidencia de cstos brganos de aurogestión sólo en un $2 \%$ de los casos. Mientras que los cuadros superiores, que apenas alcanzaban el $6 \%$ de la fuerza laboral, representaban el $10 \%$ en los consejos obreros y el $27 \%$ en los comités de gestión, llegando a ocupar la presidencia de estos organismos en un $20 \%$ y en un $28 \%$ de los casos, respectivamente. Reflejándose así la posición privilegiada de la que parte la recnocracia para ejercer y consolidar su poder c influencia. 
En cuanto al otro núcleo de poder real, la burocracia, puede decirse que su presencia y su influencia sobre la sociedad yugoslava no sólo no se vieron disminuidas, como cabría esperar de su autoproclamada posición de discreción sobre los asuntos del país, sino todo lo contrario. En contra del espíritu de la Constitución de 1953 y de sus propios estatutos, el Partido Comunista modificaba simplemente su forma de ejercer el poder; en vez de imponerlo directamente desde arriba, trataría de hacerlo indirectamente, mediante el control que representaban sus miembros apostados en los puestos clave de la estructura social: desde la empresa y la comuna a las repúblicas y a los organismos federales ${ }^{7}$, asegurándose así la presencia de la Liga Comunista a todos los niveles de la toma de decisiones. Concretamente, en el ámbito específico de la empresa, una proporción elevada de los cargos de los órganos de autogestión estaría integrada por miembros del partido, en muchos casos invitados a pertenecer a éste una vez que detentaban ya el cargo.

Tecnocracia y buroctacia constituyen, pues, dos caras de la misma moneda; ambas son la expresión de la nueva clase dominante yugoslava y compartirían un mismo objetivo, que no es otro que acaparar y mantenerse en el poder, apoyándose, para ello, en uno y otro caso, en la clase trabajadora y en el sistema de la autogestión. De ahí que la reacción de los trabajadores hacia la marcha de sus empresas haya sido de total desinterés, preocupándose, casi en exclusiva, de sus salarios y viéndose, frecuentemente, abocados a recurrir a la huelga como medio para defender sus intereses 8 .

Parece paradójico, pues, que un sistema que se crea para la emancipación de la clase obrera acabe convirtiendo a ésta en su principal damnificada. Así

7. La Liga Comunista, originariamente un partido de masas, acabaría convirtiéndose en un partido de cuadros. En 1958 - según indica Blumberg (1968) - los miembros del partido representaban alrededor del $27 \%$ de los miembros de los consejos obreros y el $37 \%$ en los comités de gestión. A conienzos de la década de los setenta dicha proporción se veria incluso incrementada, ocupando ya, respectivamente, el $31 \%$ y el $42 \%$ de los cargos de los consejos obreros y de los comités de gestión. A lo que habria que añadir la magna presencia de los miembros del partido en otras instancias donde también se tomarian decisiones que afectarian a la dinámica socioeconómica de la empresa. Así, los militantes comunistas ocupaban el $63 \%$ de los puestos en los conscjos comunales, el $64 \%$ en las cámaras económicas y el $83 \%$ en los comités populares de distrito. Sin olvidar, asimismo, que todos los puestos políticos de las repúblicas y de los organismos federales estarian ocupados por miembros del partido (de Pablo, 1976).

8. En los últimos años, la aparía y el conflicto acabarían por converrirse en las reacciones básicas de los trabajadores yugoslavos hacia la matcha de sus empresas. Ello fue debido, fundamentalmente, a su pérdida progresiva del poder en los órganos de autogestión, que, como consecuencia, sólo abordarían cuestiones secundarias, o se convertirian en meros ratificadorcs de lo que ya había sido decidido por las alcas jerarquías, ya fuesen de la dirección de la empresa o de la burocracia del partido. De ahí que, al igual que ocurre en cualquier país capitalista, los intereses de la dirección y los de los trabajadores se percibiesen como muruamente contrapuestos, y la huelga haya sido un recurso habitual empleado por éstos últimos. A este respecto, es de desracar que la mayoria de las huelgas han sido organizadas por los obreros directos de la producción, y que en un $85 \%$ de los casos han participado los obreros miembros de los órganos de aurogestion (de Pablo, 1976). 
se entiende que el sistema de autogestión yugoslava reproduzca el mismo modelo de relaciones laborales conflictivas que en principio debería de haber contribuido a eliminar, o que, de forma análoga a otros sistemas participativos, "la gestión obrera pueda considerarse como un instrumento que confiere alguna participación real y una sensación de participación a los trabajadores en una empresa industrial, pero sirve más bien para integrarlos en el sistema industrial que como fuente de decisiones" (Lane, 1976).

Sin duda, y al margen de las legítimas aspiraciones de todo pueblo a su autodeterminación, el actual conflicto yugoslavo encubre motivaciones de carácter económico y de control del poder de sus élites locales, tras la apariencia de tratarse de un asunto de carácter religioso, étnico o lingüístico. Pero, volviendo de nuevo a la autogestión, la principal lección que podemos sacar es que en modo alguno puede contribuir ésta a la transformación de la sociedad cuando queda desnaturalizada, y se convierte en un mero sistema organizativo, como de hecho no contribuyó a la vertebración de la antigua Yugoslavia.

No obstante, la autogestión tuvo consecuencias positivas; permitió, sobre todo, que una sociedad atrasada en términos culturales, sociales y económicos, pudiese superar en un plazo relativamente corto dichos inconvenientes. Sin embargo, hay muchas razones para pensar que el actual conflicto yugoslavo se debe, en gran medida, al fracaso de un verdadero socialismo autogestionario. La construcción de una sociedad autogestionaria no podría descansar, única y exclusivamente, en la propiedad social de los medios de producción, ni en un ordenamiento legal que confiriese a los trabajadores el estatus y la responsabilidad de regir la vida social y económica, sin atajar antes todos los factores que conducen a la desigualdad y a la consagración de las jerarquías. Lo que, como hemos visto, condujo inevitablemente a la formación de elitocracias, que, apoyadas en una "interesada" autogestión económica y en la descentralización administrativa, propiciaron que las repúblicas más desarrolladas del norte aprovechasen esta autonomía para frenar la redistribución de la tenta nacional, con el consiguiente estancamiento económico y social de las repúblicas subdesarroltadas del sur, sin que a ello haya sido ajena, obviamente, la lógica del mercado o, más bien, la "fragmentación del mercado", como indican los expertos de la OCDE?

9. El rérmino "fragmentación del mercado" fue acuñado por los expertos de la OCDE (1984) para referirse a la situación provocada por la aplicación de los principios autogestionarios al marco de las relaciones económicas entre las diversas repúblicas. De acuerdo con el ordenamiento legal, cada república y provincia autónoma de las que integraban el antiguo estado federai yugoslavo disponía de una amplia discrecionalidad en materia económica, sobre todo en lo que concierne a la distribución de crédiros, a la política fiscal, a la formación y conerol de precios y, en menor grado, al comercio exterior e interior.

Esta amplia autonomía de unas repúblicas a otras tuvo como consecuencia más inmediata la descoordinación en la política economica nacional, provocando, a su vez, altas tasas de desempleo y de inflacion; pero, sobre todo, propició que las diversas repúblicas arbitrasen los procedimientos adecuados para frenar la redistribución de la renta nacional en favor de sus propias economfas locales, dándose el caso de muchos productos que eran al mismo tiempo exporcados por una república e importados del extranjero por otra. 
El conflicto estaba, pues, servido. Una vez desaparecida la figura integradora que fue el mariscal Tito y desenfriada la política de bloques, las repúblicas del norte ansiaron romper los ficticios lazos que les unían a Belgrado, y para ello bastó con alimentar las diferencias que, por razones de étnia, de religión, de cultura o de historia, de hecho les separaban. Sin embargo, los herederos del poder central, con Serbia a la cabeza, en modo alguno estaban dispuestos a entender dichas aspiraciones independentistas, ante el temor de perder el dominio y el control político de estos otros territorios.

\section{Bibliografía}

BlumberG, P. (1968). Industrial Democracy: The Sociology of Participation. Londres: Constable.

CASTILlO, J. (1987). "La experiencia de autogestión yugoslava". J. F. TEZANos (ed.): La democratización del trabajo. Madrid: Sistema.

Chauvey, D. (1970). Autogestion. París: Seuil, col. Politique, núm. 41.

DE PABio, A. (1976). "La autogestión en Yugoslavia: Análisis crítico de una expericncia”. Documentación Social, núm. 21, enero-marzo, p. 99-120.

DORado, R. (1976). "La Autogestión: Principios, Experiencias y Perspectivas". Documentación Social, núm. 21, enero-marzo, p. 25-54.

Garaudy, R. (1972). L'Alternative. Changer le monde et la vie. Paris: Robert Laffont. LANE, D. (1976). "The Socialist Industrial State". Londres: Allen and Unwin, p. $143-144$.

Maestu, C.F. (1976). "La Autogestión y los Sindicatos". Documentación Social, núm. 21, enero-marzo, p. 85-98.

MarZal, A. (1986). Análisis Politico de la Empresa. Barcelona: Orbis.

OBRADOVIC, J. (1975). "Workers' Participation: Who participates?". Industrial Relations, vol. 14, p. 32-44.

OECD (1984). Economic Surveys 1984-1985: Yugoslavia. París, p. 47.

Supek, R. (ed.) (1973). Etatisme et Autogestion. París: Anthropos. 